very sharply defined in time with perhaps a double structure. And third, on the basis of 12 direction measurements, their distribution seems isotropic.

Of course, much more in the way of detailed measurements is available, and was presented. But that is just about all the evidence on which the theoreticians can build their models. Nothing daunted, the theoreticians have proceeded to do just that, as Pacini described.

The isotropy of the burst distribution provides vital information. Either the bursts originate nearby (a few hundred parsecs from the Sun), or they must be extragalactic. The intermediate case, of a distribution over a large part of our Galaxy, would reveal structure related to the structure of the Galaxy. With that proviso, Pacini happily listed the models which have been proposed: radiation from relativistic dust grains entering the Solar System; comets falling into collapsed stars; traces of "defunct" pulsars; superflares on stars; supernovae in external galaxies; birth of neutron stars; and the "first manifestation" of radio outbursts in external galaxies.

It does not really matter which, if any, of these models may turn out to be correct. What is significant is that theoreticians are prepared to toss such ideas into the melting pot, throwing them out or revising them as observations require. The observers, on the other hand, seem to wish to build complete detailed models on the basis of incomplete data, while justifying the procedure with a barrage of statistics (not always valid for small samples) and the interchangeable, largeerror graphs which I have already mentioned.

Perhaps this is a result of the lack, in some cases, of astronomical training. With experiments which simply cannot be repeated and the everyday hazards of balloon and rocket observations, something more of the pioneering attitude seems to be needed in this last frontier of observational astronomy.

But on the other hand, this earnestness among the observers is really only manifested when they get up on their hind legs to address a gathering of

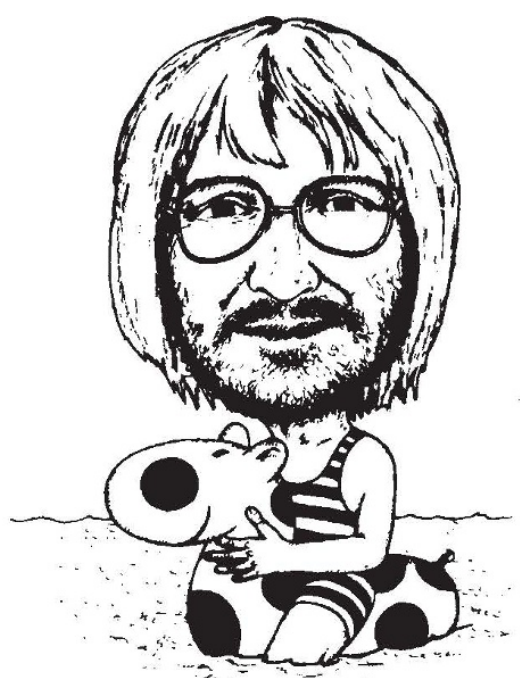

\section{Glaxo awards}

JонN Gribbin, of Nature, is among the four recipients of Glaxo Travelling Fellowships for science journalists announced on July 9. His award, in the National category, is chiefly for a series of articles on the significance of climatic change; much of this work has appeared in The Times Science Report and longer articles appeared in Nature, New Scientist and Environment and Change during 1973.

The awards, which are sponsored by Glaxo and administered in collaboration with the Association of British Science Writers, are in the form of $£ 500$ travel grants; John Gribbin will be using his award to travel to the United States and Canada during the autumn, and will be reporting for Nature on research into climatic
John Gribbin (left) lives by the sea at Brighton.

change being carried out there.

John Gribbin joined the staff of Nature in October 1970, after completing research for a $\mathrm{PhD}$ in astrophysics at the University of Cambridge. In that year, he received the First Award of the Gravity Research Foundation of New Boston for work on "Using Gravity to Determine the Nature of Superluminous Astronomical Objects"; for most of the past four years he has been in charge of the Nature-Times News Service, which reports on developments in all the sciences. As well as the interest in climatic change which has led to this award, John Gribbin is concerned about the application of science to other global problems, and is co-author of a book on earthquakes and earthquake prediction (The Jupiter Effect) which is to be published by Macmillan in September.

Fellowships in the other three categories (Radio and Television; Regional; and Trade, Technical and House Magazine) go to David Wilson (Science Correspondent of BBC Television News), Judith Hann, a freelance science journalist, and Geoffrey Watts, Deputy Editor of World Medicine. Miss Hann is the first person to win a Glaxo Fellowship for the second time; the first occasion was in 1967.

Last year's award winners included John Maddox, then Editor of Nature, in the National category. their peers. Individually or in small groups (especially after lubrication with the local Frascati wine) they appeared as intelligent people with the sense of humour needed to cope with the rigours of their trade. In some cases, they even agreed that their data were really rather vague and open to other interpretations, at least in detail

The symptoms are, indeed, very similar to those severe cases of jargonese which result when many people try to write a "scientific paper". In the long term, the answer to both problems must lie in a basic change of attitude in the direction of clarity and honesty of communication as opposed to cunning packaging which can only be interpreted by the initiated.

In the short term, since almost every scientist is willing to communicate as a human being on a face to face basis, saving the 'scientist' mask for lecturing, a solution might be to cut down on formal presentations at symposia, in favour of circulation of papers together with ample opportunity for informal discussion. At Frascati, more than 50 talks were on the official timetable (covering $2 \frac{1}{2}$ working days) and more were crammed in at short notice. Apart from the obvious benefits of a trip to Italy in June, it is difficult to see how the participants would have been less well served simply by reading the papers. The advantages of a symposium should be personal contact and the opportunity to assess the abilities of colleagues in the same field who may work on another continent; it seems that the time has certainly come when a move away from the present system, in the direction of the original "drinking party" implications of the word "symposium" could well be a good thing. 